\title{
ULTIMATE CAPACITY OF NARROW TYPE STEEL BOX SECTION FOR RAILWAY SELF-ANCHORED SUSPENSION BRIDGE UNDER BIAS COMPRESSION
}

\author{
Rui-Li Shen, Lun-Hua Bai ${ }^{*}$, Song-Han Zhang \\ Department of Bridge Engineering, Southwest Jiaotong University, 111 North Second Ring Rd., Chengdu610031, China \\ *(Corresponding author: E-mail: bailunhua@ 163.com)
}

\section{A B S T RA C T}

The steel box section, with its excellent performance, has been extensively applied in self-anchored suspension bridges. The ultimate capacity of such sections, which needs to be exactly predicted, is crucial to the safety of the whole bridge. A narrow type steel box section (NTSBS) with width to height ratio of 4.18 is deployed in Egongyan Rail Special Bridge, which is a railway self-anchored suspension bridge with $1120 \mathrm{~m}$ span in total. In order to comprehensively investigate the ultimate capacity of NTSBS, the behavior of NTSBS under the most unfavorable internal forces is herein studied by means of experiments and numerical simulations. Firstly, a representative steel box girder is selected to be an experimental rescale model and the most unfavorable internal forces are determined by computation analysis. Then, a load test is conducted on the rescale model of NTSBS girder. The experimental method is introduced, including the loading method and layout of measuring points. During this loading procedure, the prestress loss of the steel strands in the self-loading system is considered in order to improve the accuracy of the actual eccentric loading. Subsequently, a finite element (FE) model meshed by shell element is validated using the test results and is used to investigate effects of residual stress and geometric imperfections. Finally, the FE method is extrapolated to the full scale model, the actual ultimate capacity is obtained, and effect of geometric imperfections of mid webs and failure mechanism are investigated.

\section{A R T I C L E H I S T O R Y}

$\begin{array}{ll}\text { Received: } & 17 \text { October } 2017 \\ \text { Revised: } & \text { 26 July } 2018 \\ \text { Accepted: } & \text { 26 August } 2018\end{array}$

\section{K E Y W O R D S}

Narrow type steel box section;

Eccentric compressive experiment;

Finite element analysis;

Ultimate capacity;

Tee stiffener;

Local buckling

\section{Introduction}

The Egongyan Rail Special (ERS) Bridge with spans of $50+210+600+210+50 \mathrm{~m}$ (Fig. 1), which is the largest span self-suspension bridge worldwide, is located in Chongqin, China. Such a large span increases the demand for cross sections. In order to resist greater bending moment and axial force, a narrow type steel box section (NTSBS) (Fig. 2) is adopted in the bridge. Compared to steel box section applied in highway suspension bridge, of which width to height ratio is often greater than 10 and known as flat steel box section, the NTSBS has a small width to height ratio of 4.18 (18.8 $\mathrm{m}$ width and $4.5 \mathrm{~m}$ height). The NTSBS is composed of stiffened plates, thickness of top and bottom plate ranges from 32 to $44 \mathrm{~mm}$, and thickness of side webs and mid webs is $40 \mathrm{~mm}$ and $20 \mathrm{~mm}$, respectively. The diaphragm spacing is 2500 $\mathrm{mm}$, and the longitudinal stiffeners spacing ranges from 350 to $790 \mathrm{~mm}$. All the steel material has a yield stress of $420 \mathrm{MPa}$. While satisfying the traveling space of the two-line trains, the NTSBS with thick flanges and high webs can provide larger bending moment and compression resistance indeed. However, the mid webs stiffened by Tee ribs, which are more slender compared to others, may limit excellent performance of NTSBS. The mid webs of NTSBS, whose ultimate compressive strength is about $0.7-0.8$ of yield strength, are designed adopting the design rules specified in EN 1993 1-5 [1] and BS 5400 [2] to guarantee local buckling. The NTSBS are designed using Guidelines for Design of Highway Cable-stayed Bridge (GDHCB) [3], which is based on allowable load method with safety factor of 1.75 .

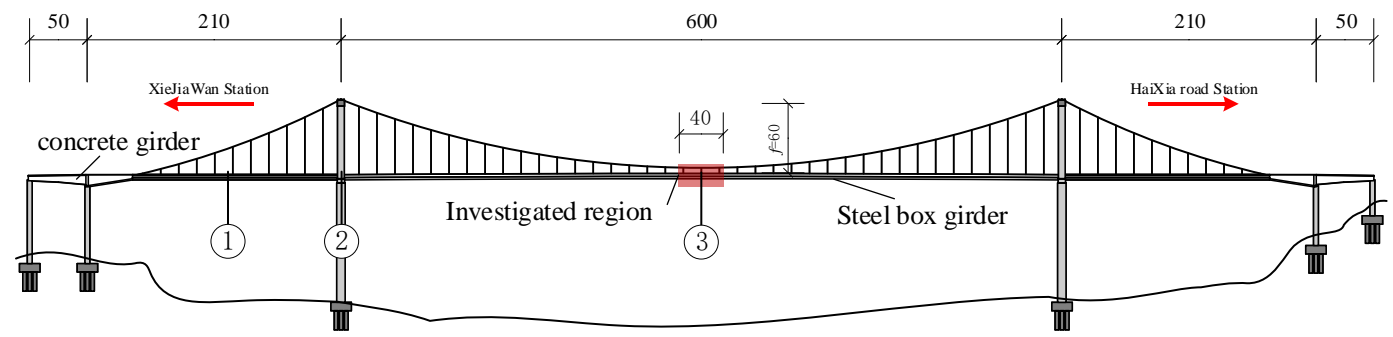

Fig. 1 General layout of ERS Bridge (m)

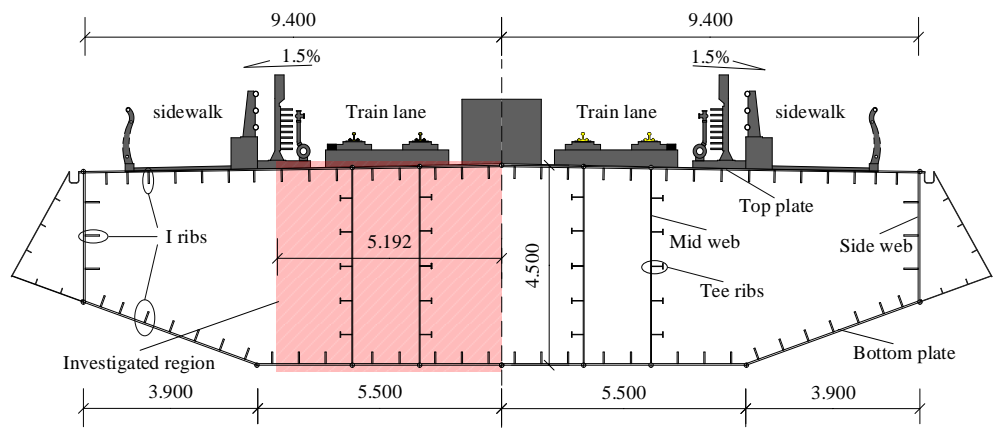

Fig. 2 The section structure of orthotropic steel box girder (m)

Generally, engineers will wonder whether ultimate capacity of the slender girder for self-anchored suspension bridge depends on the overall buckling mode. So the ultimate capacity of NTSBS should be analyzed by elastic bifurcation buckling theory. However, this is not the case. To investigate buckling behavior of the stiffening girder for self-anchored suspension bridges, deflection theory was derived by Jung et al. [4] and Hu et al. [5]. When the main beam is tied to the main cable through slings, the conclusion obtained is that any girder-dominant buckling mode does not globally occur in this type of bridge. And through the reduced scale overall bridge model test (Hu et al. [5]), overall buckling mode of the girder was not observed before the model bridge collapsed by flexural strength failure. Therefore, main concerns should be focused on second order elastic-plastic ultimate capacity of the steel box 
section incorporating material nonlinearity, residual stress and geometric imperfections.

It is important to recognize ultimate strength of stiffened plates to evaluate ultimate capacity of steel box section. Therefore, a lot of experimental and numerical studies are carried out on this topic. To verify the design strength of steel box girders for the new San Francisco-Oakland Bay Bridge, compression tests were conducted on two stiffened plates by Chou et al. [6]. The test results were compared with the 1998 AASHTO, 2002 Japanese JRA specification and finite element (FE) analysis. Test on flat steel box section of San Chaiji Bridge was carried by Li et al. [7]. It was found that the ultimate strength of web plates with open stiffeners is much lower than material yield strength, the $U$ ribs are recommended as stiffeners for the actual bridge. Through a series of numerical studies, Grondin et al. [8] concluded that overall buckling of the stiffened plate is the optimal failure mode because of its stable post buckling behavior. Shen [9] used FE models to analyze ultimate strength of welded square box section members without stiffened plates, and applications of column curves in design codes to these members was suggested. Zhang et al. [10] proposed a simplified method based on the fiber-beam element to predict strength and ductility of the thin-walled stiffened box steel pier, the local buckling of the base stiffened plate was considered in this method by two modified bilinear material models. Chen et al. [11] conducted a load test on a 1:4 scaled model of a steel arch rib to investigate buckling behavior of a convex box section of a steel arch bridge.
The results showed the effect of local buckling on the axial compression strength of the convex arch rib is modest. And normalized stress-strain relationship was proposed to describe the compressive behavior. Estefen et al. [12] have investigated the effect of geometric imperfections on the ultimate strength of the double bottom of Suezmax tanker. Matthew et al. [13] investigated local buckling of trapezoidal rib orthotropic bridge deck systems, and found the local buckling of ribs located at the rib walls and the negative moment adversely affected the local buckling strength of the ribs.

Researches on ultimate capacity of the whole bridge can be found in some literatures. Ellobody [14] used a whole double track bridge FE model to study the interaction of buckling modes in railway plate girders steel bridges, effects of bridge geometries, slenderness and steel strength on mechanical behavior and ultimate capacity of the railway bridge are discussed comprehensively. Nie et al. [15] developed a multiscale FE model to investigate the cable anchorage system of a self-anchored suspension bridge with steel box girders. In addition, the multiscale modeling method was validated by comparing with the traditional scale modeling method and full-scale modeling method. Olmati et al. [16] assessed robustness of the I-35W Minneapolis steel truss bridge.

From the above, most previous investigations were focused on mechanical behavior of flat steel box girder for highway bridges, other forms of sections for railway bridges, or local buckling of stiffened plates. However, researches on ultimate capacity of NTSBS for the railway self-anchored suspension bridge under bias compression are rarely reported.

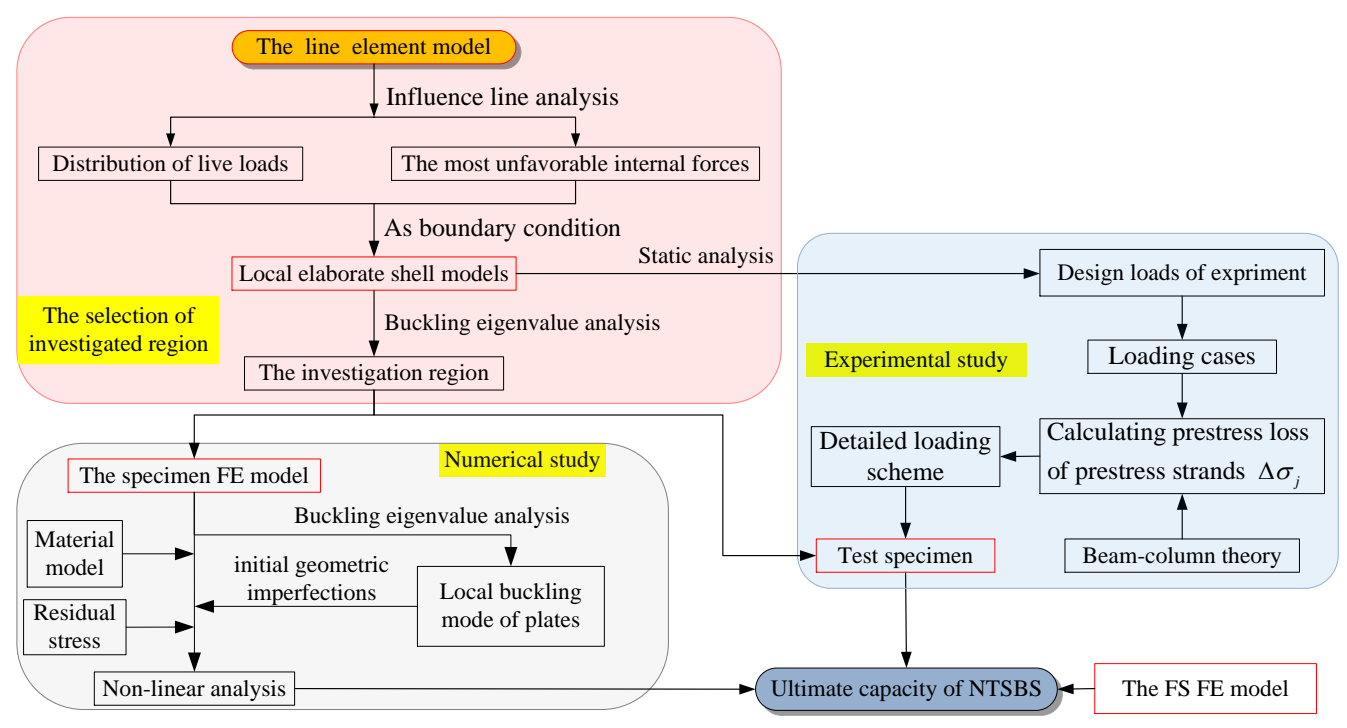

Fig. 3 Strategy of predicting the ultimate capacity of steel box girder for self-anchored suspension bridge

The main objectives of this study are to present the experimental methods and the FE modeling to understand the buckling behavior of the NTSBS, to evaluate the ultimate capacity of that and investigate effects of residual stress and geometric imperfections. A research strategy is proposed to make this study more clear, as shown in Fig. 3. This study covers the following 3 aspects: (1) The selection of segment to be investigated: since the ERS Bridge has many sections along the span, a representative section should be selected to be tested as an specimen, and experiment load conditions are also determined according to the computation results of structural analysis; (2) Experimental study: the experiment specimen is designed and fabricated based on similarity theory. The self-loading system widely used in other experiments (Chen et al. [11]; Li et al. [7]) is employed as the loading devices. And to implement the modeling of eccentric loads in the self-loading system, an algorithm for the tension of prestress strands based on beam-column theory verified by elaborate FE analysis is presented; (3) Numerical study: a parametric analysis based on the validated FE model using the test results is then conducted to investigate the effects of residual stress and initial geometric imperfections. Finally, the FE model is extrapolated to the full scale (FS) FE model, the actual ultimate capacity is obtained, and effects of local buckling of mid webs and failure mode are analyzed.

\section{The selection of investigated segment}

Three key sections are involved, namely, section (1) at middle of the side span, section (2) supported by the tower and section (3) at middle of the center span, as shown in Fig. 1. An investigated section is selected by analysis of the structural model and local elaborate shell (LES) models of the key sections, as shown in Fig. 4.
The structural model of the bridge (Fig. 4 (a)) is established in the BNLAS software (Tang et al. [17]), the main cable is simulated by catenary element, and the sling is simulated by truss element, and the tower and stiffening girder are simulated by beam element. In this model, the actual loads and pier supports are considered. The actual loads include 5 types of loads, namely, the dead load (about $350 \mathrm{kN} / \mathrm{m}$ ), the track load $(67.8 \mathrm{kN} / \mathrm{m}$ ), the crowded load $(10 \mathrm{kN} / \mathrm{m})$, the temperature (heating up to 25 centidegrees) and the transverse static wind load (about $5 \mathrm{kN} / \mathrm{m}$ ). The track load is applied as concentrated loads, while the crowded load and transverse static wind load is applied as distributed loads. In the process of solution, geometric nonlinearity is considered while material nonlinearity is not. Young's modulus is assumed as 34,500 MPa for the concrete, and as 206,000 MPa for steel, respectively. Possion's ratio is assumed as 0.2 for concrete, and as 0.3 for steel, respectively. By influence line analysis, the most unfavorable internal force of each key section and the distribution of the live loads, which are imposed as boundary conditions on LES models, are determined.

LES models are often used to accurately predict the mechanical behavior of structures (Chen et al. [11]; Nie et al. [15]). Thus, to form a preliminary understanding of the buckling behavior of the NTSBS, static and eigenvalue buckling analysis are conducted through LES models of the three segments using the finite element software ANSYS. Considering the unfavorable conditions of axial force and bending moment, 9 cases (Table 1) are analyzed. SHELL181 is used in these LES models, because it is suitable for analyzing thin to moderately-thick shell structures. The element accounts for transverse shear deformation which plays an important role in simulating behavior of thick plates. The global element size is about $500 \mathrm{~mm}$, and the element size of the key section segment is refined to about $250 \mathrm{~mm}$. In addition, a beam 188 element with length of $1 \mathrm{~mm}$ along the longitudinal direction is created at 
both ends of the LES models. One node of the beam element is positioned on the central of the section, and is coupled with all degrees of freedom of the nodes at the end section by using CERIG command. The other node of the beam element node is constrained, and is called constraint node. Boundary conditions of LES models are assumed as simple supported, as illustrated in
Fig. 4 (b)-(d). Displacement along $y$ and $z$ directions as well as rotation around $x$ are fixed at both constraint nodes of the LES models, while displacement $x$ is constrained at only one constraint node. The axial force is imposed on the constraint node whose displacement $z$ is free, and the bending moment is imposed on both constraint nodes.

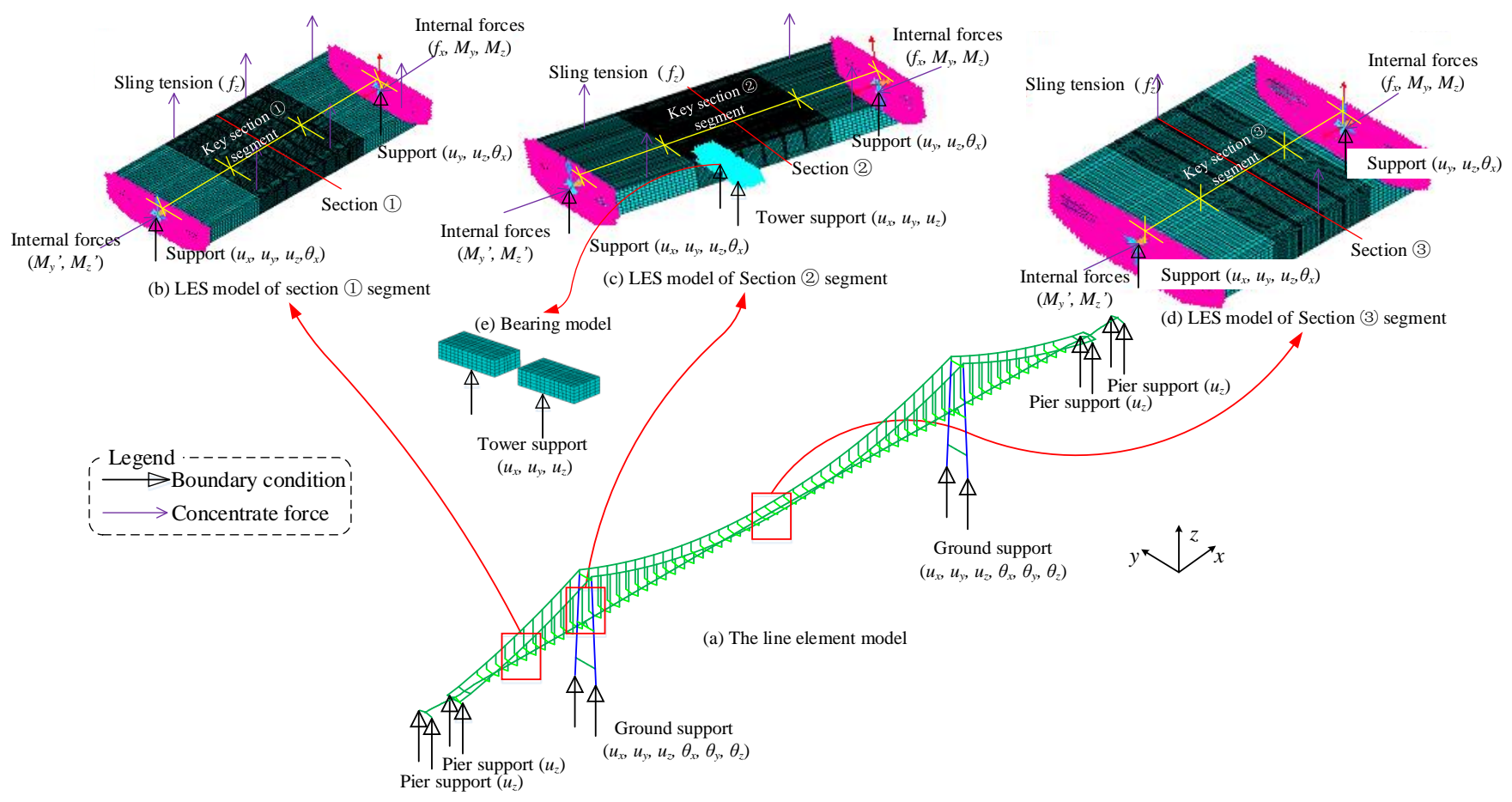

Fig. 4 The line element model and the LES models

The results of the eigenvalues buckling analysis from LES models are listed in Table 1 and reveal that local buckling of the section is sure to occur at the mid webs. Failure of the mid webs dominated by plate buckling indicates that these plates are rigidly stiffened. Failure modes of the mid webs are three half waves along the longitudinal directions. Meanwhile, buckling stress obtained from eigenvalue buckling analysis exceeds yield stress. Buckling coefficients ranging from 4.8 to 5.1 indicate risk of section buckling failure along the span is almost uniform. Accordingly, the $40 \mathrm{~m}$ segment at the middle of the center span (Fig. 1) is selected to be investigated. And experimental loads are based on the internal forces of case $\mathrm{s} 7$

Table 1

Results of the buckling eigenvalues analysis of the three shell models

\begin{tabular}{|c|c|c|c|c|}
\hline Case & $\begin{array}{l}\text { Segment to be } \\
\text { analyzed }\end{array}$ & $\begin{array}{l}\text { Live loads } \\
\text { arrangement }\end{array}$ & $\begin{array}{l}\text { Buckling } \\
\text { coefficient }\end{array}$ & Buckling positions \\
\hline s1 & & Patten $1^{*}$ & 4.84 & \multirow{9}{*}{ Subpanels on mid webs } \\
\hline $\mathrm{s} 2$ & section (1) & Patten $2^{*}$ & 4.88 & \\
\hline s3 & & Patten $3^{*}$ & 5.13 & \\
\hline s4 & & Patten 1 & 5.86 & \\
\hline s5 & section (2) & Patten 2 & 5.98 & \\
\hline s6 & & Patten 3 & 6.02 & \\
\hline s7 & & Patten 1 & 5.02 & \\
\hline s8 & section (3) & Patten 2 & 4.92 & \\
\hline s9 & & Patten 3 & 5.06 & \\
\hline
\end{tabular}

*Patten1: Axial force of the section $i$ is the most unfavorable; Patten 2: moment of the section $i$ is maximum; Patten 3: moment of the section $i$ is minimum. $i=(1)$, for case s1, $\mathrm{s} 2$ and $\mathrm{s} 3 ; i=(2)$, for case $\mathrm{s} 4, \mathrm{~s} 5$ and $\mathrm{s} 6 ; i=(3)$, for case $\mathrm{s} 7, \mathrm{~s} 8$ and $\mathrm{s} 9$.

\section{Experimental method}

3.1. Design of the experiment

The design of the scale specimen is based on the principle of stress equivalence. There are two main factors, which are the selection of investigated region cut from the overall section and the scale ratio, considered in designing the scale specimen. Limited to loading conditions, it is not realistic to use a full section model to be tested. Therefore, it is reasonable that partial section investigated (Fig. 2) which contains two slender mid webs is used to test. And the scale ratio is $1 / 4$. In this way, the specimen with total $10 \mathrm{~m}$ of span is also convenient for factory manufacturing. Noting that Q345 steel (characteristic yield strength is 345 $\mathrm{MPa}$ ) is adopted for the specimen instead of the Q420 used in the bridge because of limitations of the steel markets. Therefore, it is necessary to study the numerical analysis of NTSBS. Table 2 summarizes detailed information of the steel used in this specimen. Fig. 5 presented the general layout of the scale specimen.

Table 2

Information of steel in the specimen

\begin{tabular}{|c|c|c|c|c|c|c|}
\hline \multicolumn{2}{|c|}{ Classification of plates } & $\begin{array}{l}\mathrm{AT}^{*} \\
(\mathrm{~mm})\end{array}$ & $\begin{array}{c}\mathrm{MT}^{*} \\
\mathrm{Cal}(\mathrm{ad})^{*} \\
(\mathrm{~mm})\end{array}$ & Materials & $\begin{array}{c}f_{y}\left(\varepsilon_{y}\right) \\
\operatorname{MPa}(\mu \varepsilon)\end{array}$ & $\begin{array}{c}f_{u} \\
\text { (MPa) }\end{array}$ \\
\hline \multicolumn{2}{|r|}{ Top plates (TP) } & 42 & $10.5(10)$ & \multirow{8}{*}{ Q345 } & $349(1694)$ & 505 \\
\hline \multicolumn{2}{|c|}{ Bottom plates (BP) } & 32 & $8(8)$ & & $392(1903)$ & 521 \\
\hline \multicolumn{2}{|c|}{ Mid webs (MW) } & 20 & $5(5)$ & & $447(2170)$ & 543 \\
\hline & Diaphragms & $10 \sim 14$ & $2.5 \sim 3.5(3)$ & & & \\
\hline \multirow{4}{*}{ Ribs } & I ribs of TP & 32 & $8(8)$ & & & \\
\hline & I ribs of $\mathrm{BP}$ & 25 & $6.25(6)$ & & $378(1835)$ & 526 \\
\hline & Web of Tee ribs & 10 & $2.5(3)$ & & & \\
\hline & Flange of Tee ribs & 14 & $3.5(3)$ & & & \\
\hline
\end{tabular}

*AT: Thickness of steel plates in the actual structure; MT: Thickness of the steel plates in the specimen; $\mathrm{Cal}(\mathrm{ad})$ : Calculate values of the thickness based on the similarity principle (adjusted thickness).

A self-loading system composed of two strong loading ends, the specimen and prestress steel strands is designed. There are 8 holes at loading 
ends along the axial direction for the strands to pass through. The holes are arranged in four rows, each row of two holes. The geometric center of the holes is designed to coincide with the centroid of the section of the specimen. In addition, 15 strands, whose type is $7 \varphi 5$ with a section area of $138 \mathrm{~mm}^{2}$ and allowable stretch strength of $1395 \mathrm{MPa}$, are arranged in each hole, and are tied to the two loading ends separately. Each hole can represent a loading point. Additionally, 8 sensors are installed under the anchorage on the anchored side to precisely control loads. This specimen is supported by the bracket at the loading ends. Rubber bearings are adopted between the loading ends and lower support structures to make this model move along the longitudinal direction without difficulty. The specimen and the loading ends are fabricated separately in the factory, and assembled together in the laboratory. Lower support structures are anchored on the floor. An image of the self-loading system installed is shown in Fig. 6.

\subsection{Loading method and verification}

The experimental loads are designed by considering the actual most unfavorable internal force and effect of rescaling. The internal force of the partial section is extracted based on isolation method, which is based on selecting the nodes at the partial section of LES model (3) and integrating the resultant forces using FSUM command. The design loads are conversed by the similarity ratio relationship, and listed in Table 3. According to Guidelines for Design of Highway Cable-stayed Bridge, the minimum applied load should be 1.75 times the designed internal force. In other words, the ultimate bearing capacity of the NTSBS, even influenced by local buckling of the mid webs, geometric imperfections and residual stress, should be no less than 1.75 times the design loads. So 13 loading cases in total are planned at present (Table 4), the maximum load can reach 1.9 times the design loads. The axial force and bending moment should be imposed in proportion
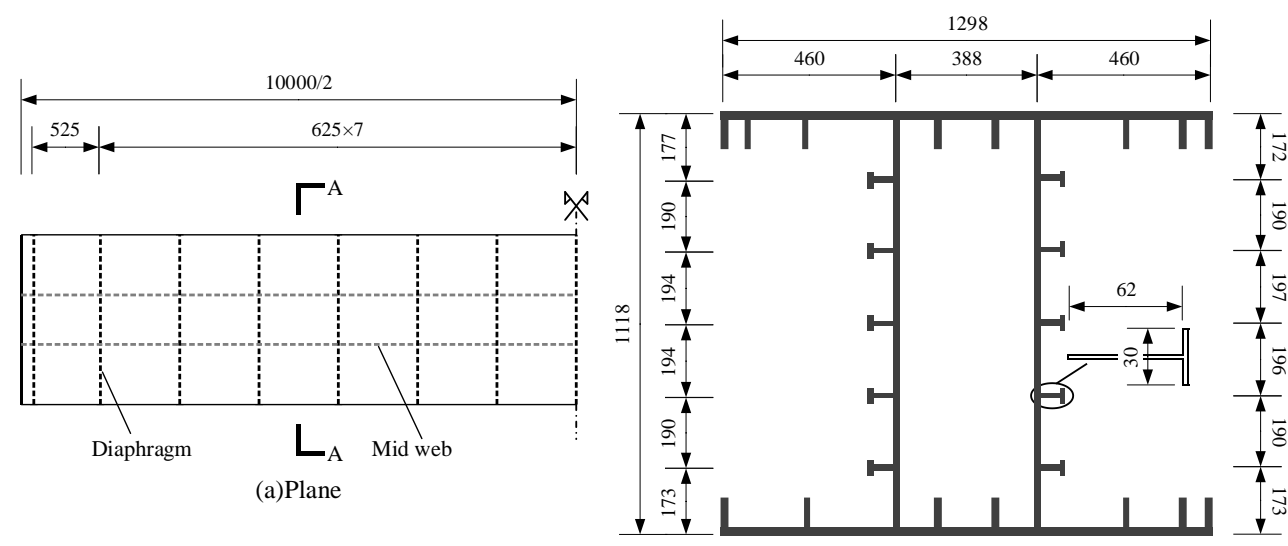

(b)A-A section

Fig. 5 General layout of model (mm)
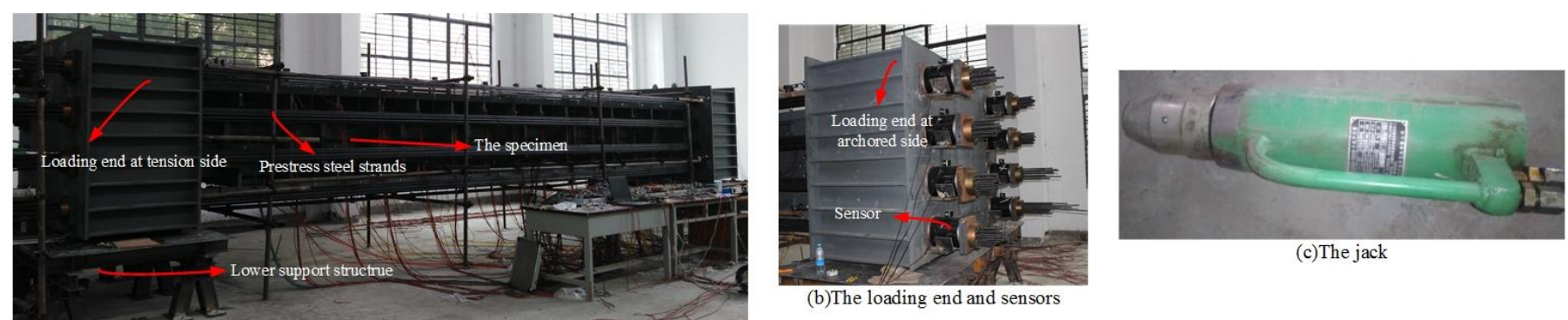

(b)The loading end and sensors

(c)The jack

(a)The self-loading system

Fig. 6 The self-loading system installed

Table 3

Conversion results of the actual design internal force on the specimen

\begin{tabular}{cccc}
\hline & $\begin{array}{c}\text { Axial force } F_{\mathrm{d}} \\
(\mathrm{kN})\end{array}$ & $\begin{array}{c}\text { Moment in plane } M_{\mathrm{yd}} \\
(\mathrm{kN} \cdot \mathrm{m})\end{array}$ & $\begin{array}{c}\text { Out-of-plane Moment } M_{z \mathrm{~d}} \\
(\mathrm{kN} \cdot \mathrm{m})\end{array}$ \\
\hline The section (3) & 3084473 & $109384^{*}$ & 176340 \\
$\begin{array}{c}\text { The investigated } \\
\text { region }\end{array}$ & 91225 & 54621 & Included in $F_{\mathrm{d}}$ \\
The specimen & 5702 & 853 & Included in $F_{\mathrm{d}}$ \\
\hline
\end{tabular}

*: positive bending direction is defined as the bending about which the top plate is in compressive state.

To simulate the eccentric loads of case 1 to 13 , both the total force of each loading point (TFELP) and the tension of each prestress strand (TEPS) should be determined. In order to easily adjust loads, the jack (Fig. 6(c)) which stretches a single prestress strand each time is used. To make sure of the uniformity of the stress of the strands at each loading point after the stretching is finished, the tension of the strands stretched by the jack should be different because of the prestress loss of the prestress strands (PLPS). In this way, stress of steel strands at one loading point can be uniform and unexpected fracture of any one strand can be avoided. The computing method of the values of TFELP and TEPS are introduced in detail in this section.

A simplified plane model of the self-loading system is proposed according to structural mechanics, as illustrated in Fig. 7. This model can be divided into two parts: Part 1 reflects the balance relationship between the section of the specimen and the prestress strands, and is used to calculate the TFELP; Part 2 reflects the compatibility of deformation, and is used to calculate PLPS and TEPS.

The $F$ and $M$ of each loading cases are objective loads and should be equal to eight TFELPs accumulated. Assumptions are made that 4 TFELPs in the top two rows equal $F_{1}$ and 4 TFELPs in the bottom two rows equal $F_{2}$. Therefore, $F_{1}$ and $F_{2}$ are given by force equilibrium equations:

$$
\begin{aligned}
& F=\sum F_{i}=4 F_{1}+4 F_{2} \\
& M=\sum F_{i} l_{i}=2 F_{1} h_{1}+2 F_{1} h_{2}-2 F_{2} h_{3}-2 F_{2} h_{4}
\end{aligned}
$$

Thus, $F_{1}$ and $F_{2}$ in the loading cases studied are figured out, and the results are listed in Table 4.

The loads applied on strands compress the girder along the axial direction, resulting in the prestress loss of strands which had been already tensioned. On the basis of the deflection equation of the beam-column, an algorithm of PLPS in the self-loading system is put forward. And the following assumptions are made:

- The loading ends are seen as rigid body; 
- $\quad$ Prestress loss caused by vertical displacement of the loading point is neglected;

- Prestress loss caused by the sag effect of the strands is ignored.

As indicated in Fig. 7, once unknowns $\Delta_{1}, \Delta_{2}, \Delta_{3}$ and $\Delta_{4}$ are solved, it can be easy to determine PLPS of each prestress strand. The algorithm for solving such unknown parameters is proposed herein, considering one of the strands in row $i$ stretched by the jack.

Table 4

Loading cases

\begin{tabular}{cccccc}
\hline Cases & Compressive force $F(\mathrm{kN})$ & Bending moment $M(\mathrm{kN} \cdot \mathrm{m})$ & $F_{1}(\mathrm{kN})$ & $F_{2}(\mathrm{kN})$ & Notation \\
\hline 1 & 1500 & 224.39 & 258.5 & 124.2 & \\
2 & 3000 & 448.79 & 516.9 & 248.4 & \\
3 & 4500 & 673.18 & 775.4 & 372.6 & \\
4 & 5700 & 852.70 & 982.1 & 471.9 & $1.0 F_{\mathrm{d}}$ \\
5 & 6500 & 972.38 & 1120.0 & 538.2 & \\
6 & 7000 & 1047.18 & 1206.1 & 579.6 & \\
7 & 7500 & 1121.97 & 1292.3 & 621.0 & \\
8 & 8000 & 1196.77 & 1378.4 & 662.4 & \\
9 & 8500 & 1271.57 & 1464.6 & 703.8 & \\
10 & 9000 & 1346.37 & 1550.8 & 745.2 & \\
11 & 9500 & 1421.17 & 1636.9 & 786.6 & $1.7 F_{\mathrm{d}}$ \\
12 & 10000 & 1495.97 & 1723.1 & 828.0 & \\
13 & 11000 & 1645.56 & 1895.4 & 910.8 & \\
\hline
\end{tabular}

While the jack stretched strands in row $i$, the deflection equation of the test beam is expressed as

$$
-E I w^{\prime \prime}=2 F_{i} w+M_{i}
$$

where, $E$ is the elastic modulus of steel, $2 F_{i}$ is defined as the tension force of row $i, M_{i}$ is the bending moment caused by $2 F_{i}$, and $I$ is the moment of inertia of the specimen section. The general solution of this constant coefficient second order non-homogenous differential equations is given by:

$w=A \sin k_{i} x+B \cos k_{i} x-\frac{M_{i}}{2 F_{i}}$

where, $k_{i}=\sqrt{2 F_{i} / E I}$. Then, by introducing boundary conditions, $A$ and $B$ are solved:

$$
\begin{aligned}
& w(x=0)=B-\frac{M_{i}}{2 F_{i}}=0 \\
& w(x=l)=A \sin k_{i} l+B \cos k_{i} l-\frac{M_{i}}{2 F_{i}}=0
\end{aligned}
$$

Thus, $A=\frac{M_{i}}{2 F_{i}} \frac{1-\cos k_{i} l}{\sin k_{i} l}, B=\frac{M_{i}}{2 F_{i}}$.

The angle of rotation $\theta$ of the girder is given by:

$$
\left\{\begin{array}{l}
\tan \theta(x=0)=w^{\prime}(x=0)=k_{i} \frac{M_{i}}{F_{i}} \frac{1-\cos k_{i} l}{\sin k_{i} l}=k_{i} h_{i} \tan \frac{k_{i} l}{2} \\
\tan \theta(x=l)=w^{\prime}(x=l)=-k_{i} \frac{M_{i}}{F_{i}} \frac{1-\cos k_{i} l}{\sin k_{i} l}=-k_{i} h_{i} \tan \frac{k_{i} l}{2}
\end{array}\right.
$$

$\Delta_{j i}$, which represents the axial displacement at the position of row $j$ caused by $2 F_{i}$, is obtained through the geometric relation:

$$
\Delta_{j i}=\Delta_{e i}+2 h_{j} \tan \theta
$$

where, $\Delta_{e i}$ denotes the compression of the central axial of the test beam caused by $2 F_{i}$. Thus, the sum axial displacement at the position of row $j, \Delta_{j}$ can be accumulated if several forces of $2 F_{1}, 2 F_{2}, 2 F_{3}$ and $2 F_{4}$ act on the loading ends together. $\Delta_{j}$ is given by the following equation:

$\Delta_{j}=\sum \Delta_{j i}=l \sum \frac{2 F_{i}}{E A_{g}}+2 h_{j} \sum k_{i} h_{i} \tan \frac{k_{i} l}{2}$

where, $A_{g}$ is the area of the specimen section. Obviously, there is a nonlinear relationship between $\Delta_{j}$ and $F_{i}$. With $\Delta_{j}, \Delta \sigma_{j}$ representing PLPS, is expressed as:

$$
\Delta \sigma_{j}=E_{p} \frac{\Delta_{j}}{l}
$$

where, $E_{p}$ is the elastic modulus of the prestress strand. Eq. (8) is verified by the FE model of the self-loading system. According to loading process in the actual experiment, 4 jacks are used for each load case, and loading begins to simultaneously stretch the strands at the position of row 2 and 3, and finishes by simultaneously stretching the strands of the other two rows. Accordingly, there are 30 times to stretch strands in one case. It means that the loads of case $i$ are applied in 30 load steps. To indicate the order of the tensioned strands, the strands are numbered, as shown in Fig. 8. In this way, Eq. 8 can be extended as:

$\Delta \sigma_{R L 3 n, i}=\left\{\begin{array}{l}\frac{E_{p}}{l}(16-n)\left(\Delta_{32}+\Delta_{33}\right)+\frac{E_{p}}{l} 15\left(\Delta_{31}+\Delta_{34}\right), i=1 \\ \frac{E_{p}}{l} 15\left(\Delta_{32}+\Delta_{33}\right)+\frac{E_{p}}{l} 15\left(\Delta_{31}+\Delta_{34}\right), i>1\end{array}\right.$

$\Delta \sigma_{R L 2 n, i}=\left\{\begin{array}{l}\frac{E_{p}}{l}(16-n)\left(\Delta_{22}+\Delta_{23}\right)+\frac{E_{p}}{l} 15\left(\Delta_{21}+\Delta_{24}\right), i=1 \\ \frac{E_{p}}{l} 15\left(\Delta_{22}+\Delta_{23}\right)+\frac{E_{p}}{l} 15\left(\Delta_{21}+\Delta_{24}\right), i>1\end{array}\right.$

$\Delta \sigma_{R L 1 n, i}=\left\{\begin{array}{l}\frac{E_{p}}{l}(16-n)\left(\Delta_{11}+\Delta_{14}\right), i=1 \\ \frac{E_{p}}{l} 15\left(\Delta_{11}+\Delta_{14}\right)+\frac{E_{p}}{l} 15\left(\Delta_{12}+\Delta_{13}\right), i>1\end{array}\right.$

$\Delta \sigma_{R L 4 n, i}=\left\{\begin{array}{l}\frac{E_{p}}{l}(16-n)\left(\Delta_{41}+\Delta_{44}\right), i=1 \\ \frac{E_{p}}{l} 15\left(\Delta_{41}+\Delta_{44}\right)+\frac{E_{p}}{l} 15\left(\Delta_{42}+\Delta_{43}\right), i>1\end{array}\right.$

$\Delta_{i j}=l \frac{2 F_{j}}{15 E A_{g}}+2 h_{i} k_{j} h_{j} \tan \frac{k_{j} l}{2}$

where, $\Delta \sigma_{R L j n, i}$ represents the prestress loss of number R/Lj- $n$ strand in loading case $i$. Hence, TEPS $f_{R L j n, i}$ is calculated as:

$f_{R L j n, i}=\Delta \sigma_{R L j n, i}+F_{k i} / 15, k=1,2$

where, $F_{k i}$ represents values of $F_{1}$ or $F_{2}$ in loading case $i$. Taking case 1 and case 2 as example, the loading scheme is formulated according to this algorithm, as shown in Fig. 9.

The self-loading system is modeled in the ANSYS software, each part of the system is precisely simulated, as illustrated in Fig. 10. This model is only adopted to verify Eq. 9-14. SOLID45 is used for anchorages and rubber bearings, the element size is around $20 \mathrm{~mm}$ for anchorages and around $80 \mathrm{~mm}$ for rubber bearings. LINK8 is used for strands, and the element number is meshed as one for each strand. SHELL181 is used for steel plates of specimen and loading ends, and the element size is about $60 \mathrm{~mm}$ for the specimen and $80 \mathrm{~mm}$ for the loading ends. The element size of loading ends surface 
contacting to the specimen and anchorages is refined to about $40 \mathrm{~mm}$. The total shell element number is 155,328, and the solid and rod element are 18,689 and 120 , respectively. The boundary conditions are defined as: $u_{x}=u_{y}=u_{z}=0$ at the bottom surface the of rubber bearing on one side; and $u_{x}=u_{y}=0$ on the opposite side. The tension forces of the strands are modeled by the falling temperature method. The geometric nonlinear effects is taken into consideration. The static analysis is conducted by 30 load steps in case $i$.

Two situations are included in the FE analysis: prestress loss and no loss of prestress. The former characterize that the TEPS is calculated by Eq. 14 . The later characterize that $\Delta \sigma_{R L j, i}$ is ignored in the TEPS. Results of stress of strands are compared in Table 5. And it reveals that only the stretched forces which include the prestress loss calculated by Eq. 14 are applied on the strands, the load can be transferred as expected, and the uniformity of the stress of the strands can be guaranteed.

It should be noted that the tension of the strands only included the prestress loss caused by the elastic compression of the specimen, but anchorage retraction should also be taken into account in the practical loading procedure. Therefore, the loads applied are controlled more precisely by combining the loading scheme and the sensors shown in Fig. 6 (b).

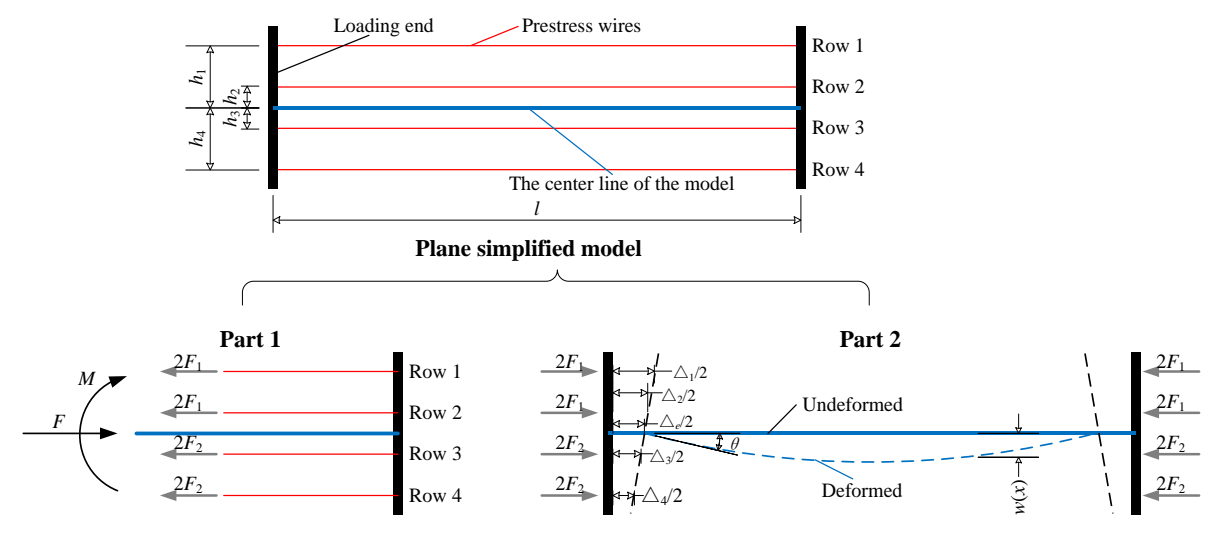

Fig. 7 The simplified model of the self-loading system
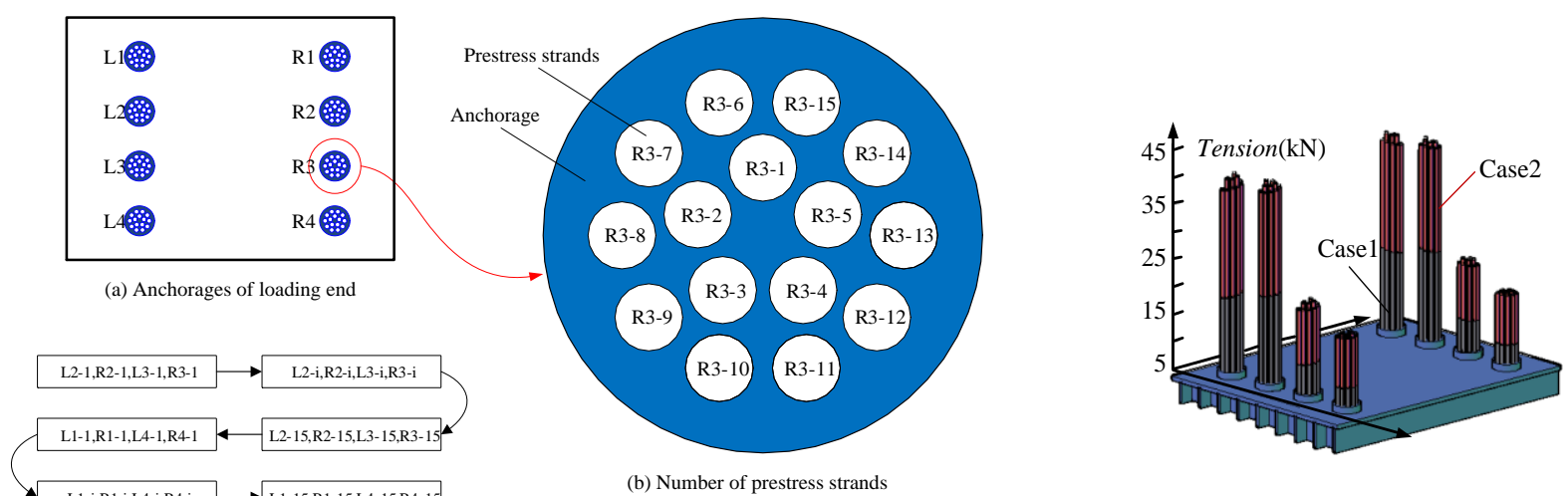

(c) The order of tensioning prestress strands

Fig. 8 Number of the srands

Fig. 9 Tensile load of strands

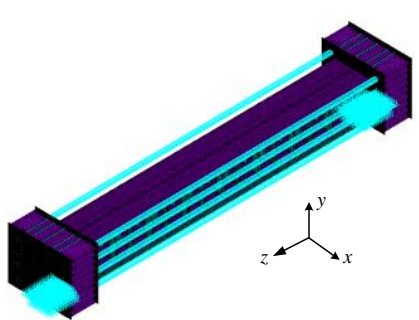

(a)General view

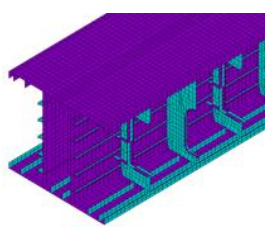

(b)The specimen

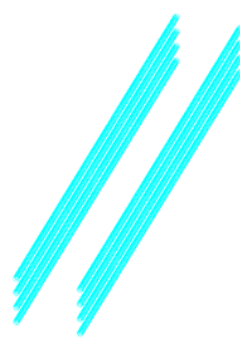

(c)Prestress strands

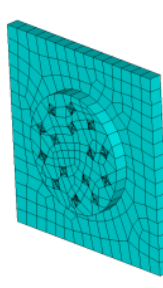

(d)Anchorage

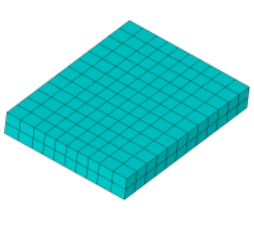

(e)Rubber bearing

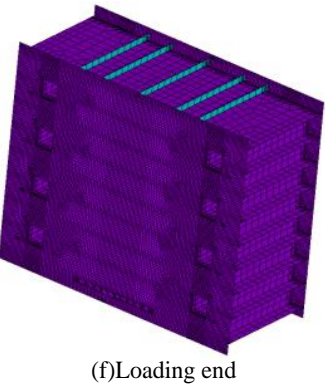

(f)Loading end

Fig. 10 FE model of the self-loading structure 
Table 5

Results of stress of strands

\begin{tabular}{|c|c|c|c|c|c|c|}
\hline \multirow[b]{2}{*}{ Strands } & \multicolumn{3}{|c|}{ Case1 } & \multicolumn{3}{|c|}{ Case2 } \\
\hline & $\begin{array}{l}\mathrm{SRC}^{*} \\
(\mathrm{MPa})\end{array}$ & $\begin{array}{l}\text { SRNC }^{*} \\
(\mathrm{MPa})\end{array}$ & $\begin{array}{c}\text { OS }^{*} \\
(\mathrm{MPa})\end{array}$ & $\begin{array}{l}\mathrm{SRC}^{*} \\
(\mathrm{MPa})\end{array}$ & $\begin{array}{l}\text { SRNC }^{*} \\
(\mathrm{MPa})\end{array}$ & $\begin{array}{c}\mathrm{OS}^{*} \\
(\mathrm{MPa})\end{array}$ \\
\hline R1-1 R1-15 & $125.8 \sim 129.2$ & $102.2 \sim 121.7$ & 126.1 & $250.9 \sim 256.0$ & $193.1 \sim 213.2$ & 252.2 \\
\hline L1-1 L1-15 & $125.8 \sim 128.9$ & $101.9 \sim 121.6$ & 126.1 & $250.3 \sim 255.4$ & $192.6 \sim 212.7$ & 252.2 \\
\hline $\mathrm{R} 2-1 \sim \mathrm{R} 2-15$ & $125.7 \sim 129.8$ & $93.3 \sim 108.4$ & 126.1 & $251.6 \sim 258.4$ & $190.0 \sim 205.9$ & 252.2 \\
\hline L2-1 L2-15 & $125.0 \sim 129.7$ & $92.7 \sim 108.3$ & 126.1 & $250.5 \sim 257.5$ & $189.2 \sim 205.5$ & 252.2 \\
\hline R3-1 R3-15 & $57.8 \sim 61.3$ & $33.8 \sim 46.4$ & 57.4 & $115.7 \sim 122.1$ & $70.2 \sim 84.0$ & 114.8 \\
\hline L3-1 L3-15 & $57.2 \sim 60.9$ & $33.3 \sim 46.4$ & 57.4 & $114.8 \sim 120.8$ & $69.5 \sim 83.6$ & 114.8 \\
\hline $\mathrm{R} 4-1 \sim \mathrm{R} 4-15$ & $57.3 \sim 58.8$ & $50.5 \sim 55.7$ & 57.4 & $115.6 \sim 119.2$ & $93.0 \sim 99.2$ & 114.8 \\
\hline L4-1 L4-15 & $57.2 \sim 58.7$ & $50.4 \sim 55.7$ & 57.4 & $115.2 \sim 118.8$ & $92.6 \sim 98.9$ & 114.8 \\
\hline
\end{tabular}

*SRC: Stress range considering prestress loss; SRNC: Stress range not considering prestress loss; OS: Objective stress of each strand.

\subsection{Measuring points arrangement}

Massive measuring points of the displacement of the specimen and the strains of the plates are adopted to fully understand the limit state of this specimen. A placement scheme is put forward, as shown in Fig. 11. Two longitudinal strain-measurement lines are placed on the top plate and its ribs respectively. In addition, 1 longitudinal strain-measurement line is placed on the bottom plate and its ribs respectively. Additionally, 2 longitudinal displacement meters containing 6 points are placed on the upper and bottom plate. There are 13 longitudinal strain-measurement lines in total placed on mid webs, 7 lines placed on the subpanels and 6 lines placed on the Tee stiffeners. Besides, to obtain compression of the girder, 4 dial gauges are arranged on the surface of each loading end.

\section{Finite element modeling}

The load ends and the prestress strands are ignored to reduce computational cost in the nonlinear FE model, and they are equivalently replaced by the internal forces. The nonlinear FE model incorporating residual stress and geometric imperfections is established in ANSYS. The specimen FE model is meshed by SHELL181 and the element size is about $50 \mathrm{~mm}$. In addition, a beam 188 element with length of $1 \mathrm{~mm}$ along the longitudinal direction is created at both ends of the FE model. One node of the beam element is positioned on the central of the section, and is coupled with all degrees of freedom of the nodes at the end section by using CERIG command. The other node of the beam element node is constrained, and is called constraint node. The boundary conditions are set to keep the force transmission the same as the experimental model. Hence, displacement along $x$ and $y$ directions as well as rotation around $z$ are fixed at both constraint nodes of this model, while displacement $z$ is constrained at only one constraint node. The axial force is imposed on the constraint node whose displacement $z$ is free, and the bending moment is imposed on both constraint nodes. The finished model and boundary conditions are illustrated in Fig. 12 (a). To take the plate material nonlinear behavior into account, an elastic perfectly plastic constitutive model incorporating a Von Mises yield surface and a bilinear isotropic hardening rule is employed. Young's modulus is assumed as $206,000 \mathrm{MPa}$ and Poisson's ratio is assumed as 0.3 . The yield strength is strictly consistent with the plates measured and is assumed to be $345 \mathrm{MPa}$ for the unmeasured plates. Therefore, the yield strength is assumed as 349 MPa for top plates, $392 \mathrm{MPa}$ for bottom plates, $447 \mathrm{MPa}$ for mid webs, and $378 \mathrm{MPa}$ for ribs of bottom plates, respectively.

Previous studies (Shen. [9]; Sheikh et al. [18]; Luka et al. [19]; Shi et al. [20]; Yuan et al. [21]) have shown that the magnitude and shape of geometric imperfection have significant influence on the ultimate capacity of steel structures. For the box girder model, a number geometric imperfection mode can be taken into considerations. However, only local plate imperfections are assumed, and is inserted in the shape of the lower eigenvalue buckling modes. These plate buckling modes are 3 half waves shape, and eigenvalue buckling analysis must be performed for each plate. Referring to EN 1993-1-5 [1], which recommends that the equivalent magnitude of geometric imperfections should be a minimum between $a / 200$ and $b / 200$ ( $a$ and $b$ are length and width of the subpanel, respectively), the magnitude of geometric imperfections in this study is assumed as $7 \mathrm{~mm}$, about a/100. In addition, the patterns of rectangular uniform residual stresses recommended by Chatterjee [22] are adopted for lack of residual stress measurement, and only one type of residual stress is accounted for, namely, the longitudinal residual stress occurring in plates. The tension residual stress is assumed as yield strength, while the compressive residual stress is assumed as 30 percent of the yield strength. The residual stress is implied as initial stress vial the command ISFILE, which implies that the 5 integration points of each shell element have the same initial stress value. Geometric imperfections are modelled via UPGEOM command. The geometric imperfections and residual stress imposed on the specimen FE model are illustrated in Fig. 12 (b) and (c), respectively.

From above, there are four steps to complete the FE analysis. Firstly, the FE model is established without any imperfection and a static solution is conducted to acquire the stiffness matrix of the model. Secondly, plate buckling modes are solved by an eigenvalue buckling analysis. Thirdly, updating the coordinates of nodes in the FE model and implying residual stress, a nonlinear ultimate capacity analysis is conducted using the Newton-Raphson iterative procedure. The axial force and bending moments should be large enough to obtain the ultimate capacity of the specimen. Fourthly, the strain and displacement of the measuring points are extracted to obtain the ultimate capacity and load displacement curves.

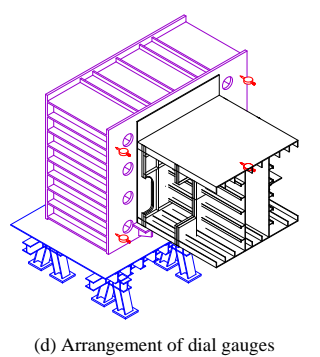

(d) Arrangement of dial gauges
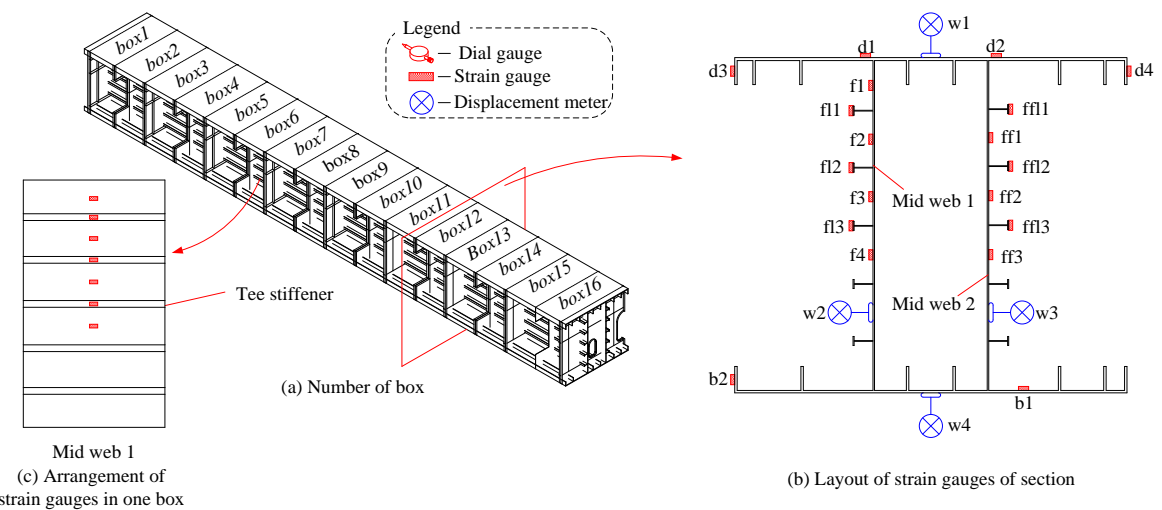

(b) Layout of strain gauges of section

Fig. 11 The layout of measure points 


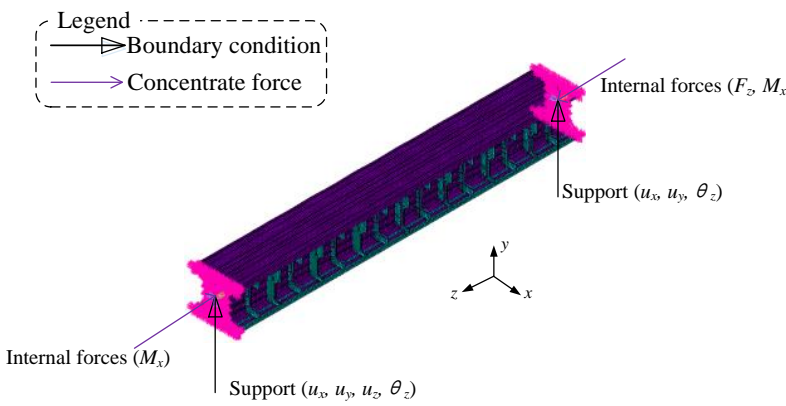

(a) The FE model of specimen

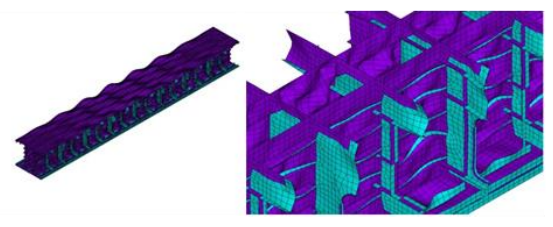

(b) Geometric imperfections

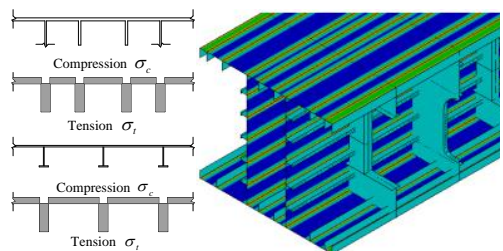

(c) Residual stress

Fig. 12 The FE model of specimen in ANSYS

\section{Results and discussion of the rescale model}

\subsection{Validate of FE model}

Measuring points at subpanels and stiffeners are assumed in uniaxial stress state. Taking mid web as an example, the distribution of measured strain along longitudinal direction calculated by FE model is compared with the test results, as shown in Fig. 13. When the stress level of cross section is lower, such as case 1 , strain of measuring points can be very accurately predicted by FE model. When the stress level of cross section is higher, such as case 11, a certain fluctuation along the longitudinal direction is found among the strain of the measuring points and can be predicted relatively precisely by the assumed defect FE model. In addition, it indicates that the proposed loading method can precisely control the loads applied, and the loads applied can be transmitted to the box girder sections effectively.

The load and displacement curves, including the load compression curve and the load mid-span deflection curve, are show in Fig. 14. It can be seen that the deformation predicted experimentally is slightly large than that predicted numerically, but the trends of curves between the test and FE model results are basically the same. The load and strains of measuring lines curves are shown in Fig. 15 and Fig. 16. The overall agreement between the test and FE analysis results can be clearly illustrated when $F$ does not exceed about $1.2 F_{\mathrm{d}}$, except for a few measuring lines $\mathrm{d} 4$, ff1 and b2. However, the developing trends of strain of d4, ff1 and b2 correlate well with test. When $F$ exceeds $1.2 F_{\mathrm{d}}, \mathrm{FE}$ analysis results seem to underestimate strain. It may be caused by the complex non-linear mechanical behavior stemming from non-linear material and randomness of initial imperfections which are only simply assumed in FE model.

Overall, FE model can be able to predict strain of stiffened plates and load and displacement relationships of the specimen, and it will be mentioned later that the FE model can also be capable of predicting the deformed modes of the mid webs.

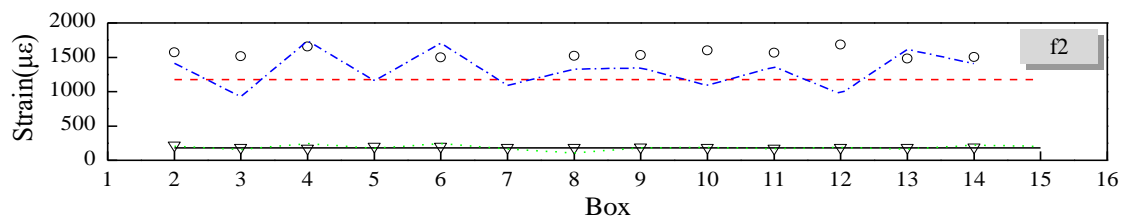

$\boldsymbol{\nabla}$ Measured \& Case 1

- No any imperfections \& Case 1

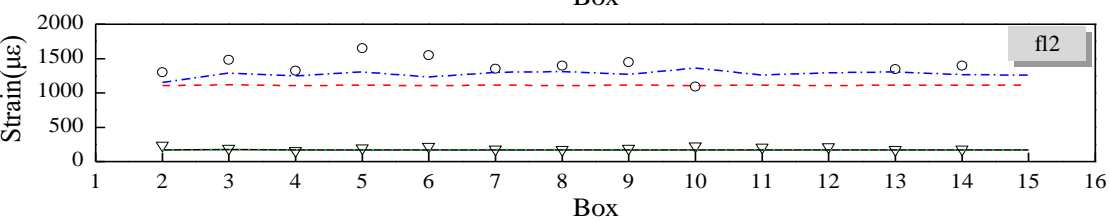

RS $0.3 \sigma_{y}$ and $7 \mathrm{~mm}$ GI \& Case 1

- Measured \& Case 11

- - . . No any imperfections \& Case 11

----- RS $0.3 \sigma_{y}$ and 7mm GI \& Case 11

Fig. 13 Change of strain along the longitudinal direction.
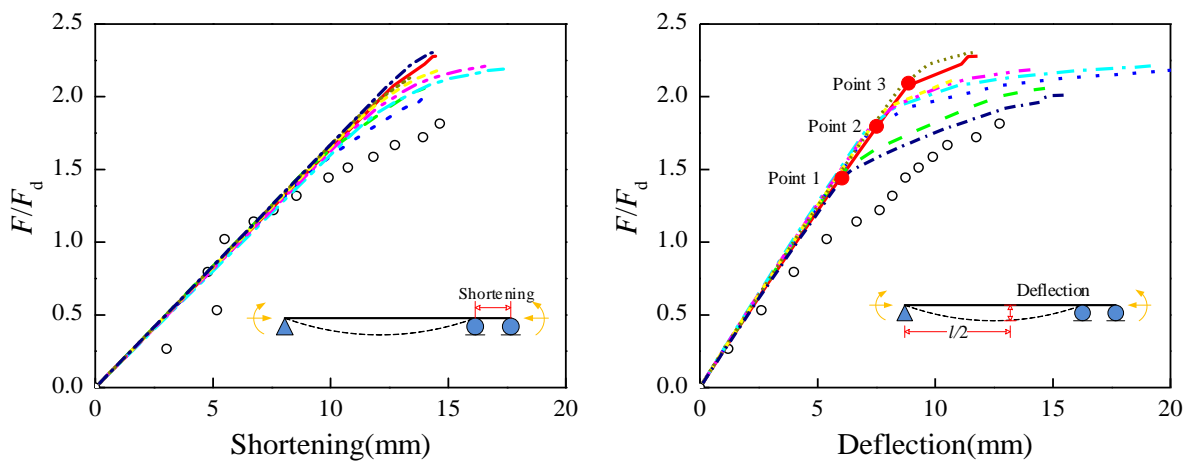

No RS \& $7 \mathrm{~mm}$ GI

RS $0.3 \sigma_{y} \&$ No GI

-.. $\quad$ RS $0.125 \sigma_{y} \& 7 \mathrm{~mm} \mathrm{GI}$

-.- RS $0.125 \sigma_{y} \& 5 \mathrm{~mm} \mathrm{GI}$

-.- RS $0.125 \sigma_{y} \& 3 \mathrm{~mm} \mathrm{GI}$ RS $0.125 \quad \sigma_{y} \& 1 \mathrm{~mm} \mathrm{GI}$

......... No any imperfection

RS $0.3 \sigma_{y} \& 7 \mathrm{~mm} \mathrm{GI}$

- Measured

Fig. 14 Relationship between load and deformation 


\subsection{Failure mode and ultimate capacity}

When the applied load of the test model is up to case 11 , no failure or buckling of the specimen is observed. Continuing stretching the prestress strands, the readings of the meters controlling the sensors increase. Therefore, this model structure still has bearing capacity. However, some local large deflection of the Tee stiffeners at mid webs has been seen by naked eye observation after loading case 13, and painting of the Tee ribs has also been peeling off. Furthermore, strains of parts of measuring points in mid webs and top plates exceed yield strain, for example, d3, d1 and $\mathrm{f} 1$ measuring lines, as shown in Fig. 17. At the end of the loading, the Tee ribs deform stably and no significant damage is found in their flanges. This phenomenon indicates that the specimen does not fail. Through further observation, two kinds of outplane deformation modes of the Tee ribs can be summarized: the similar symmetric mode and the anti-symmetric mode. Fig. 18 illustrates the deformation modes of the Tee ribs at the mid webs. Based on the experiment results, out-plane deformation of Tee ribs occurs during the loading process.
And these deformed shapes have been predicted numerically using the finite element model. One potential buckling mode of the mid webs should be flexural and torsional buckling of Tee ribs, and is caused mainly by the uneven stress distribution of the Tee ribs along the web height, which leads to the out-plane deflection of flanges of the Tee ribs.

Since the obvious failure deformation does not take place under the load applied, the failure mode of the reduced scale model under the ultimate load is obtained by FE model, as illustrated in Fig. 18. Under the ultimate load, the stresses of bottom plates and diaphragms are small, while the stresses of other plates are approximate to yield strength, plastic zone is formed along the span. It indicates that the specimen model fails to resist larger applied load due to material yield of top plate and mid webs. It is observed that plate buckling of mid webs and flexural and torsional buckling of Tee ribs occur before the specimen fails. Although local buckling of mid webs, flexural failure due to steel yield dominates the structure. The ultimate capacity of FE model with residual stress and geometric imperfections taken into account reaches 2.01 $F_{\mathrm{d}}, 5$ percent larger than $1.9 F_{\mathrm{d}}$ the experimental maximum load.
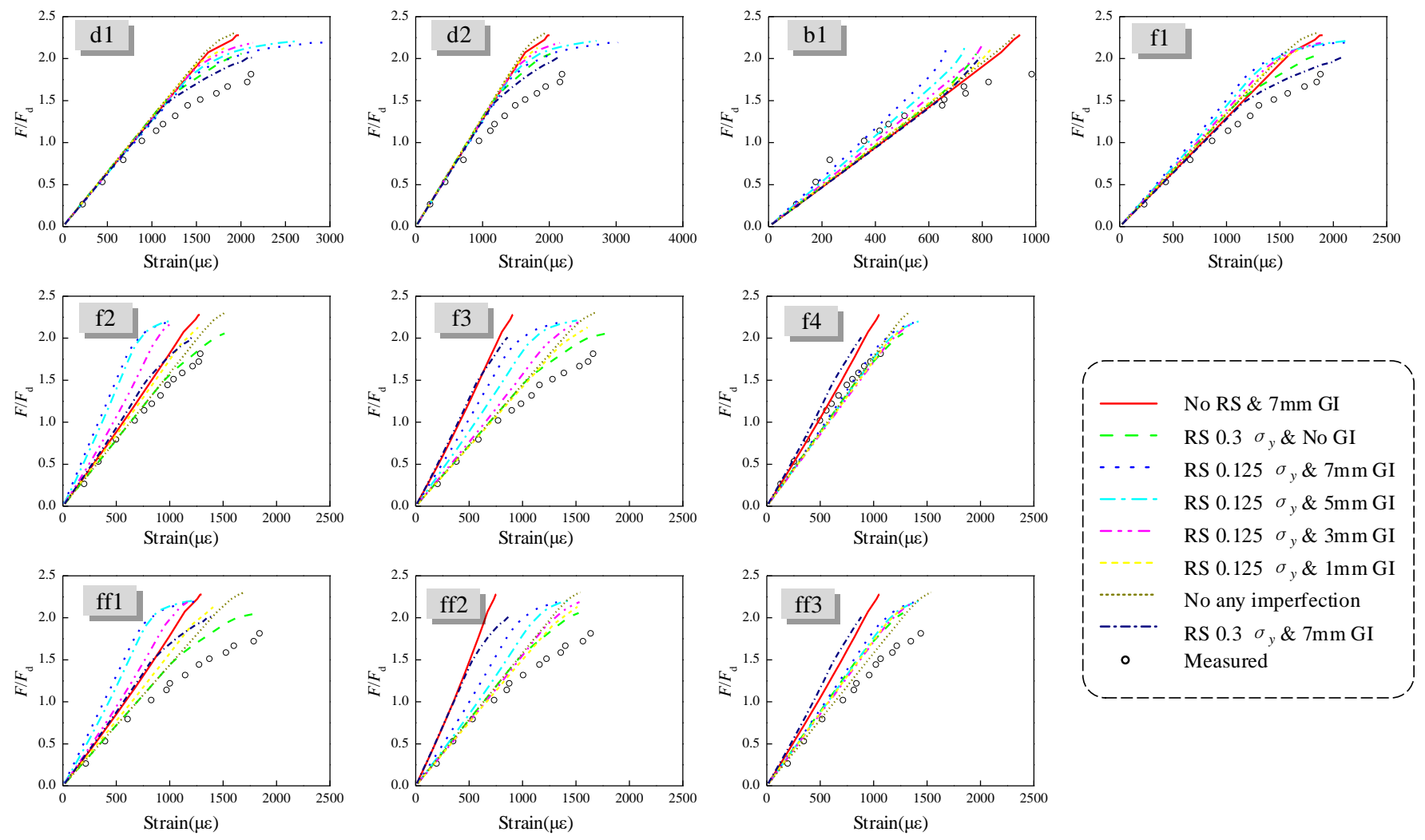

Fig. 15 Relationship between subpanel average and measured strain 

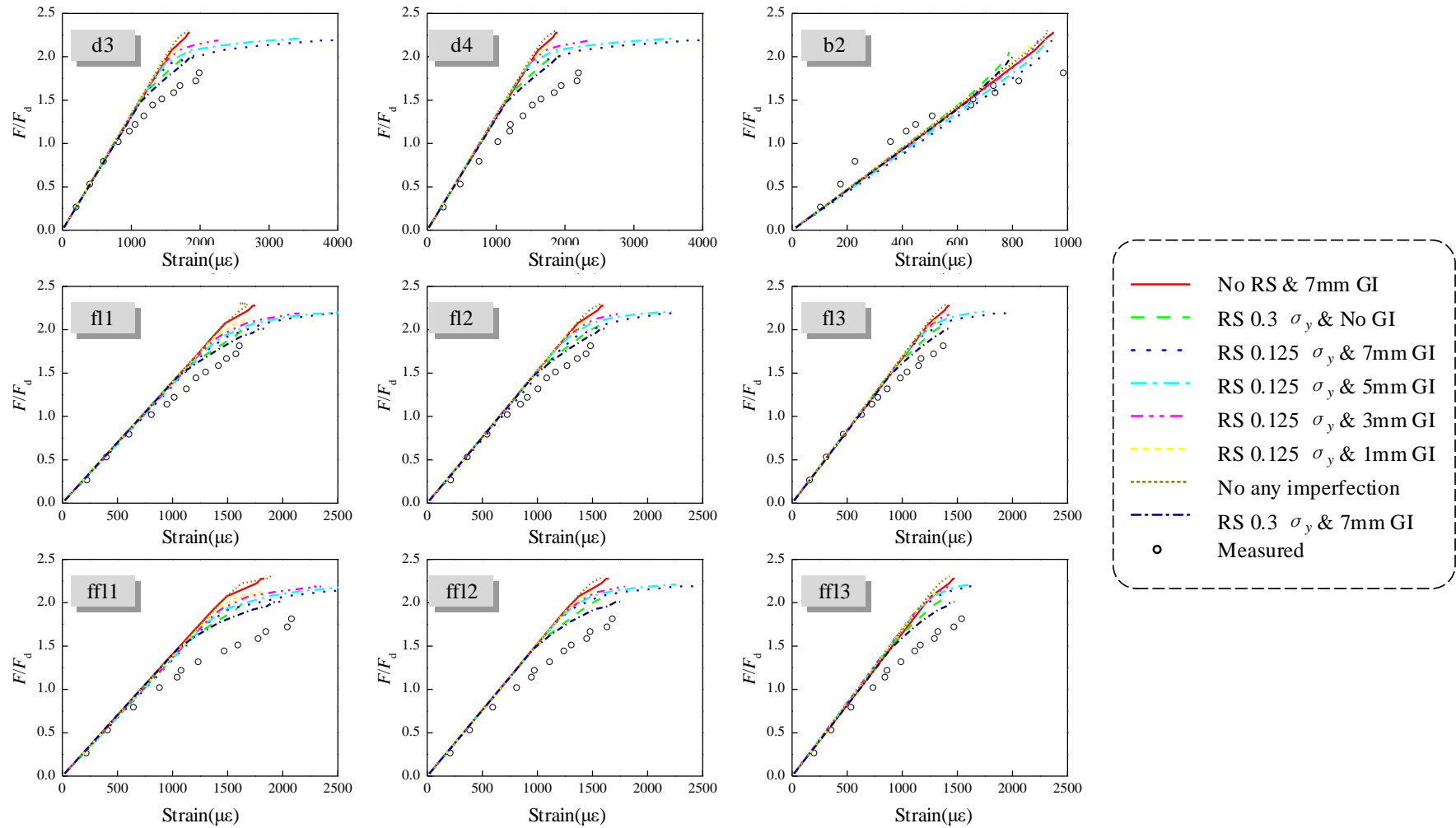

Fig. 16 Relationship between stiffeners average and measured strain

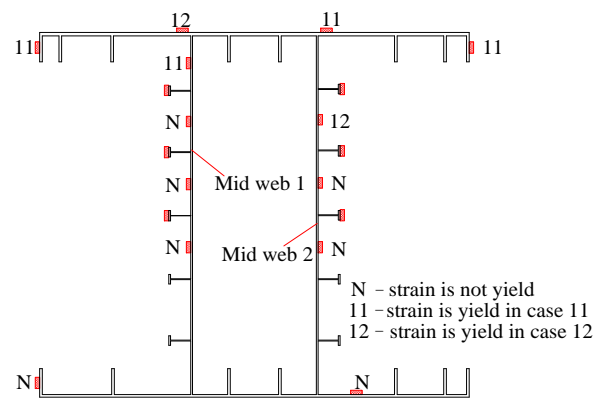

Fig. 17 Yield point distribution of section

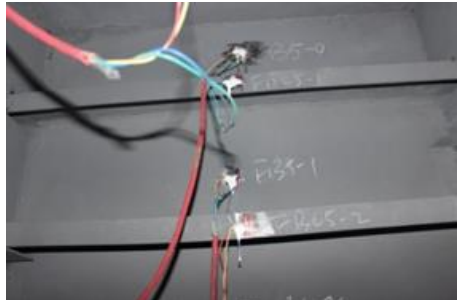

(a) Symmetric deformation of Tee ribs in box 5

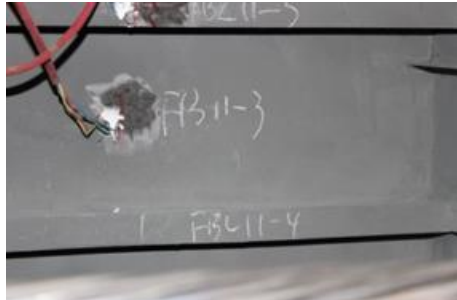

(b) Anti-symmetric deformation of Tee ribs in box 11

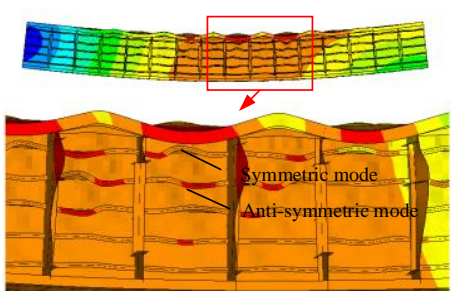

(e) Deformation by FEA

(d) Anti-symmetric mode

Fig. 18 Deformation modes of Tee ribs

\subsection{Effects of residual stress and geometric imperfections}

Eight cases are analyzed to investigate effects of residual stress, geometric imperfections and buckling mode on behavior of the specimen. In Fig. 14, Fig. 15 and Fig. 16, the legend "RS $0.3 \sigma_{\mathrm{y}}$ and $7 \mathrm{~mm} \mathrm{GI"} \mathrm{is} \mathrm{short}$ for " compressive residual stress of 30 percent of the yield strength and 7 mm magnitude of geometric imperfections", which is actual considered in FE model. And the meaning of other legends and so on.

Three cases are studied to investigate effects of residual stress on mechanical behavior of the specimen. The residual stress is assumed as three levels, namely, compressive residual stress in the plate of zero, 12.5 and 30 percent of the yield strength. The magnitude of geometric imperfections is taken as $7 \mathrm{~mm}$. As shown in Fig. 14(b), Point 1, 2 and 3 represents beginning of bending stiffness degradation. The different position of these points demonstrate that as the compressive residual stress varies from zero to 30 percent of yield strength, The bending stiffness is degenerated earlier with 2.1 $F_{\mathrm{d}}$ changing to $1.5 F_{\mathrm{d}}$. However, it seems that residual stress has slight influence on the axial stiffness since there is no turning point observed in the load compression curve. On the other hand, both curves showed that the ultimate capacity drops from 2.27 to 2.01 times $F_{\mathrm{d}}$, dropped by about 13 percent, as compressive residual stress increases.

As the compressive residual stress is assumed as 12.5 percent of the yield strength, four cases are studied to investigate effects of magnitude of geometric imperfections. It is observed that the 4 load and displacement curves almost coincide with each other, only slight reduction of ultimate capacity occurs as the magnitude of geometric imperfections increases. However, strains of measuring points are compared to indicate that the deformation of local stiffened plate is heavily influenced by geometric imperfections, as shown in Fig. 15 and Fig. 16.

As show in Fig. 14, by comparing results between two cases, which are no geometric imperfections with compressive residual stress of 30 percent yield strength and $7 \mathrm{~mm}$ magnitude geometric imperfections with compressive residual stress of 30 percent yield strength, respectively, it is found that the geometric imperfections mode with assumed 3 half waves has 
slight influence on strain of measuring points, bending stiffness, axial stiffness and ultimate capacity.

In general, the specimen seems to be more sensitive to residual stress than geometric imperfections and buckling mode; and the ultimate capacity and bending stiffness are more susceptible to residual stress than the axial stiffness; the local strain is greatly affected by magnitude of geometric imperfections.

\section{The full scale model}

\subsection{FS FE model}

To eliminate the effect of rescale, the full scale narrow type steel box girder with section (3) can be modeled adopting the same method employed in modeling the specimen. The full scale model has length of $40 \mathrm{~m}$. SHELL181 is used and the element size is about $150 \mathrm{~mm}$. The mesh size is found accurate enough to model this structure by comparing with a more fine mesh size of $100 \mathrm{~mm}$. The beam 188 elements are still created to play the same role as in the specimen FE model. The boundary conditions are assumed as simply supported. Both axial force and bending moment are imposed on the constrain nodes. The load conditions are listed in Table 3. The residual stress, geometric imperfections and nonlinear material behavior are all taken into account. The yield strength for all plates is assumed as 420 $\mathrm{MPa}$. The tension residual stress is assumed as yield strength, while the compressive residual stress is assumed as 30 percent of the yield strength.

Due to different geometric imperfections assumed, two full scale FE models are created for the analysis of NTSBS's ultimate capacity.

Case F1. In the first model, it should be noted that only geometric imperfections of mid webs is modeled because the mid webs are more prone to buckle, and is assumed three half waves in longitudinal directions. In addition, the magnitude of geometric imperfections is assumed as $28 \mathrm{~mm}$. The full scale FE model is shown in Fig. 19.

Case F2. The second model is assumed without geometric imperfections.

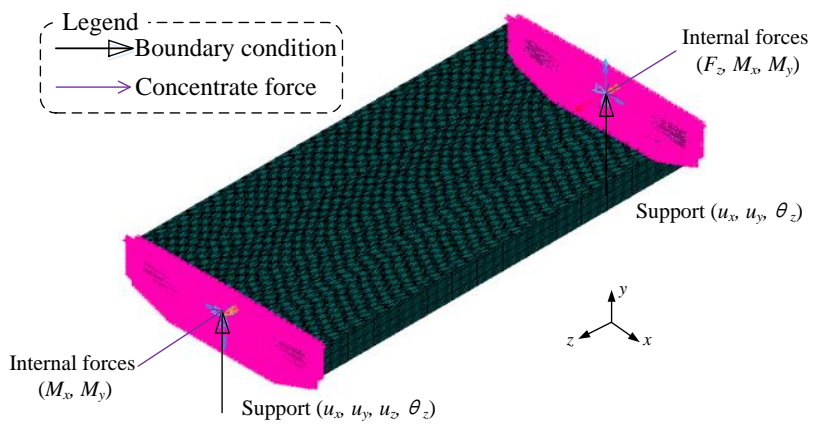

(a) FOS model

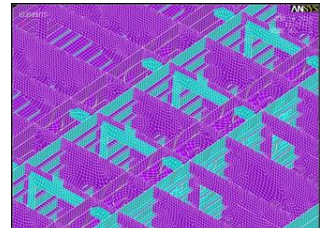

(b) Geometric imperfecions

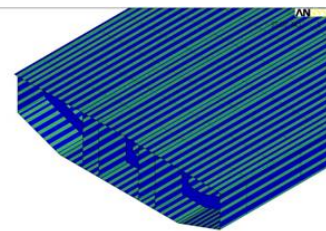

(c) Residual stress

Fig. 19 FS model in ANSYS

\subsection{Failure mode and ultimate capacity}

For Case F1, the analysis reveals that the top plate yields first, followed by mid webs. Plate buckling mode and Tee ribs tripping mode are also observed. The results indicate that the NTSBS exhibits the expected failure mode, with plates and stiffeners of mid webs both reaching the yield strength until eventual collapse. Increasing the applied load, the final collapse of the NTSBS is caused by flexural strength failure. Fig. 20 shows the von Mises stress distributions and failure sequences in case F1. Similar to the case F1, the first elements to fail are the top plate in the case F2. Furthermore, a large area of top plates and mid webs yielding is also observed.

The load and deformation curves are plotted as shown in Fig. 21. It can be shown that the relationship is linear when applied load is below minimum requirements of 1.75 times design loads by GDHCB. And as the load increases, the load versus deformation curves become nonlinear, which confirms that inelastic deformation occurs. The NTSBS's ultimate capacity is $2.37 F_{\mathrm{d}}$ in case $\mathrm{F} 1$, and $2.44 F_{\mathrm{d}}$ in case $\mathrm{F} 2$. It can be known that there is $2.8 \%$ difference in ultimate capacity between the two cases. Therefore, geometric imperfections assumed has slightly influenced on NTSBS's ultimate capacity.

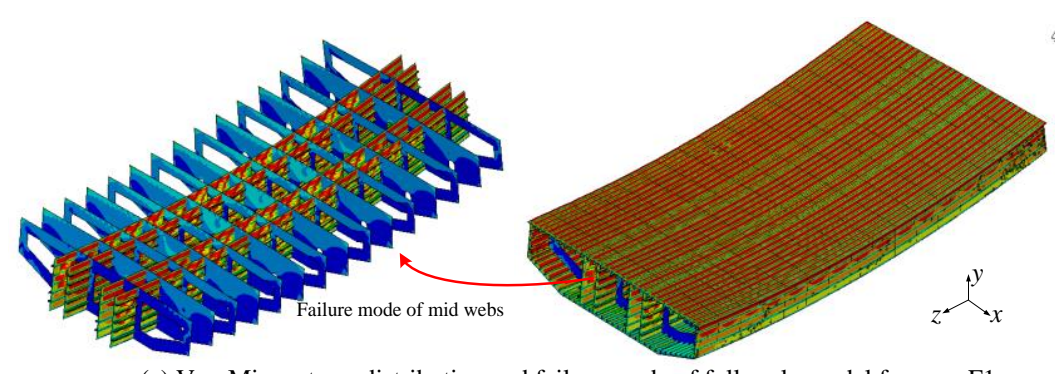

(a) Von Mises stress distribution and failure mode of full scale model for case F1
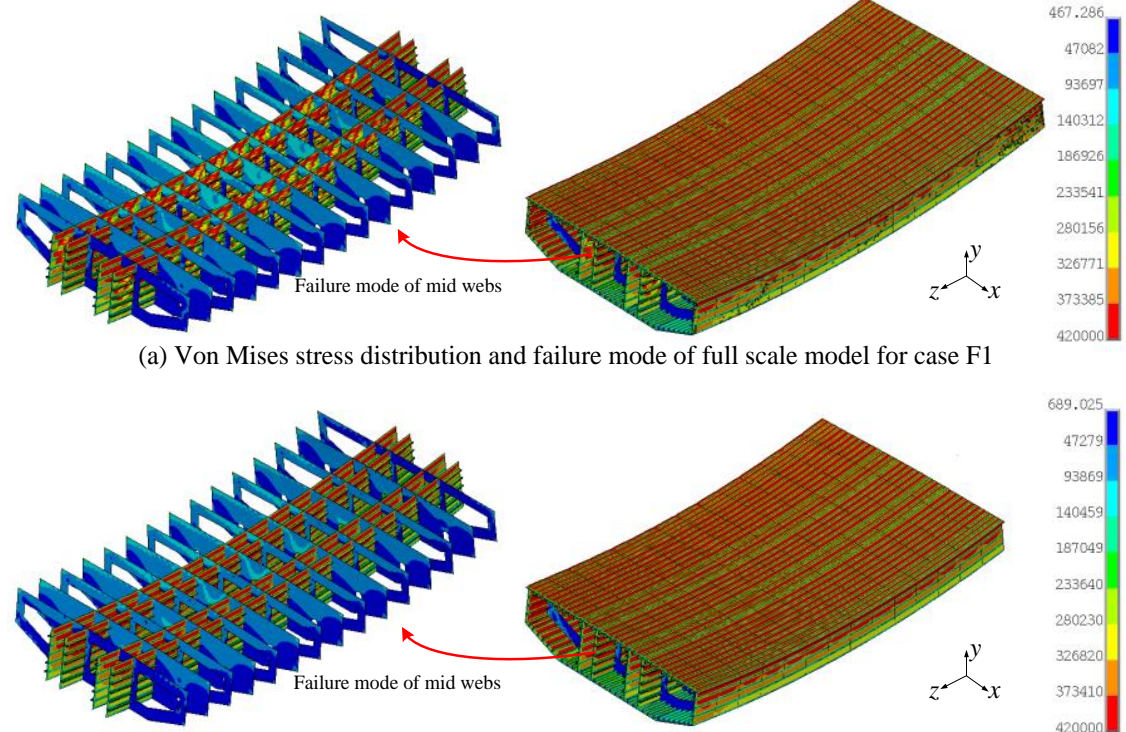

(b) Von Mises stress distribution and failure mode of full scale model for case F2

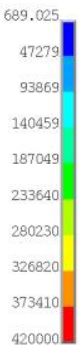

Fig. 20 Von Mises Stress distribution and failure mode of full scale model 

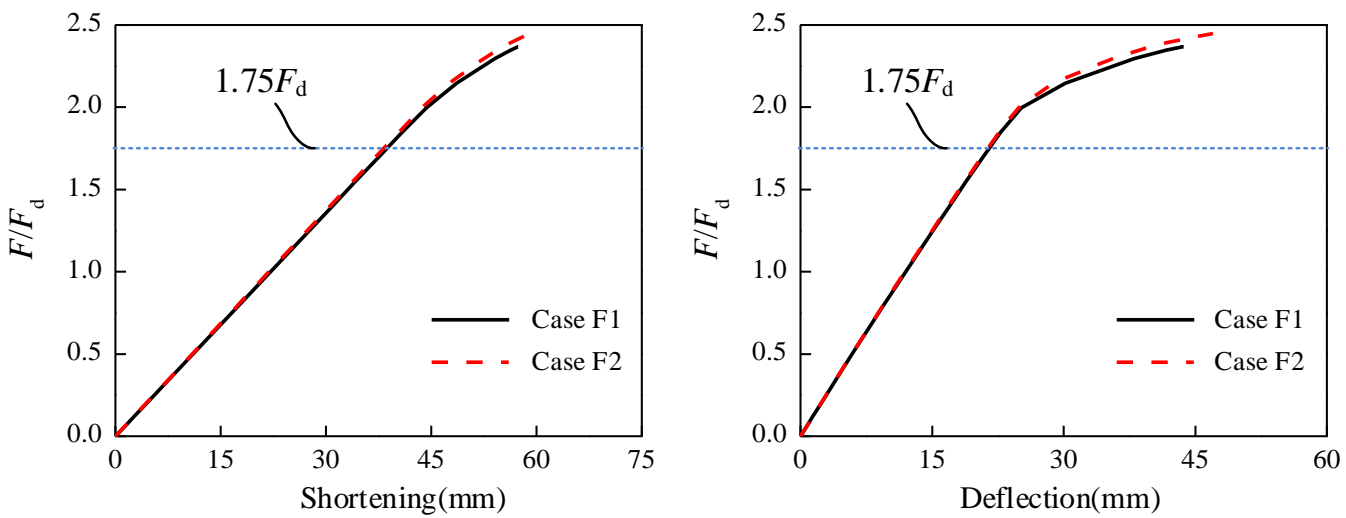

Fig. 21 Relationship between load and deformation of the full scale model

\section{Conclusions}

The ultimate capacity of NTSBS for ERS Bridge is investigated experimentally and numerically. Elastic buckling coefficients of different segments under different loading conditions are obtained by analyzing the structure model and the LES models, and compared to determine the investigated region of NTSBS. An experiment is carried out to understand the ultimate behavior of NTSBS under bias compression. The FE models of the specimen and full scale model are studied to investigate effects of residual stress, geometric imperfections on ultimate behavior of NTSBS. Based on the experimental and FE analysis results, the main conclusions can be summarized as follows:

1. The designed loading device and loading method proposed can effectively simulate the eccentric compressive loads.

2. It is concluded that based on the comparisons that the FE modeling incorporating residual stress and geometric imperfections is capable of predicting the fluctuation of strain along the longitudinal direction, the load strain curves, the load deformation curves and failure modes of the specimen. The fluctuation of strain along the longitudinal direction is mainly affected by geometric imperfections, and occurs when the stress level becomes high, as in case 11. By means of FE analysis, the load strain curves and load deformation curves of the specimen both develop two stages: linear behavior stage and nonlinear behavior stage, and nonlinear behavior occurs when load is up to 1.2 $F_{\text {d. }}$. It should be emphasized that Tee ribs deform remarkably as symmetric mode and anti-symmetric mode before the specimen fails. The specimen fails by strength failure of flexure, which is also a plastic collapse mode with a large of plastic zone detected on the top plate and mid webs.

3. By comparison of FE analysis results, the NTSBS seems to be more sensitive to residual stress than geometric imperfections. As the compressive residual stress increases, ultimate capacity and bending stiffness drops more significantly than the axial stiffness. The local strain is greatly affected by magnitude of geometric imperfections. Therefore, in the process of NTSBS fabrication, it is necessary to ensure that the residual stress needs to be controlled. In addition, plate welding deformation should be controlled to reduce the effect of geometric imperfections on local mechanical behavior of mid webs.

4. To obtain actual ultimate capacity of the NTSBS, the FS FE model is analyzed. It reveals that the sequence of plates failure under the most unfavorable internal forces. The top plate yields first, followed by mid webs. As the load increases, the structure fails due to the formation of large area plastic zone on top flanges and mid webs. The similar conclusion can be drawn that the geometric imperfections of mid webs has slightly influence on the ultimate capacity of NTSBS based on results of the two typical models. Compared with the experimental model, integrity of the FS model makes the ultimate capacity greater, and the FE analysis results of NTSBS's ultimate capacity indicate that this section is properly designed with a sufficient safety margin.

\section{Acknowledgements}

This paper was financially supported by the National Natural Science Foundation of China (Grant No. 51178396/E080505).

\section{Reference}

[1] European Committee for Standardization, Design of Steel Structures. Part 1-5: Plated Structural elements, Brussels, Belgium, 2003

[2] British Standard Institution, BS5400: Part 6, Steel, Concrete and Composite Bridges-part 6: Specification for Materials and Workmanship, London, British, 1999.

[3] Chongqing Communications Technology Research \& Design Institute, Guidelines for Design of Highway Cable-stayed Bridge. Guidelines for Design of Highway Cable-stayed Bridge, Beijing, China, 2007.

[4] Jung M.R, Jang M.J., Attard M.M. and Kim M.Y., "Elastic stability behavior of self-anchored suspension bridges by the deflection theory", International Journal of Structural Stability \& Dynamics, 17(4), 1-23, 2016

[5] Hu J. H., Wang L.H., Shen R.L., Xiang J.J. and Tang M.L., "Research on the stability of long span self-anchored suspension bridges", Journal of Hunan University, 35(5), 12-15, 2008.

[6] Chou C.C., Uang C.M. and Seible F., "Experimental evaluation of compressive behavior of orthotropic steel plates for the new San Francisco-Oakland Bay Bridge", Journal of Bridge Engineering, 11(2), 140-150, 2006.

[7] Li L.F., Shao X.D. and Yi W.J., "Model test on local stability of flat steel box girder", China Journal of Highway and Transport, 20(3), 60-65, 2007.

[8] Grondin G.Y., Elwia A.E. and Cheng J.J.R., "Buckling of stiffened steel plates-a parametric study", Journal of Constructional Steel Research, 50(2), 151-175, 1999.

[9] Shen H.X., "Ultimate capacity of welded box section columns with slender plate elements", Steel and Composite Structures, 13(1), 15-33, 2012.

[10] Zhang J., Wang C. L. and Ge H., "A simplified method for seismic performance evaluation of steel bridge piers with thin-walled stiffened box sections", Advanced Steel Construction, 10(4), 372-384,2014.

[11] Chen K.M., Wu Q.X., Nakamura S. and Chen B.C., "Experimental and numerical study on compressive behavior of convex steel box section for arch rib", Engineering Structures, 114(1), 35-47. 2016

[12] Estefen S.F., Chujutalli J.H. and Soares C.G., "Influence of geometric imperfections on the ultimate strength of the double bottom of a suezmax tanker", Engineering Structures, 127(5), 287-303, 2016.

[13] Yarnold M.T., Wilson J.L., Jen W.C. and Yen B.T., "Local buckling analysis of trapezoidal rib orthotropic bridge deck systems", Bridge Structures, 3(2), 93-103, 2007.

[14] Ellobody E., "Interaction of buckling modes in railway plate girder steel bridges", thin-walled structures, 115(6), 58-75, 2017

[15] Nie J.G., Zhou M. Wang Y. H. Fan J.S. and Tao M.X "Cable anchorage system modeling methods for self-anchored suspension bridges with steel box girders", Journal of Bridge Engineering, 19(2), 172-185, 2014

[16] Olmati P., Gkoumas, K., Brando F. and Cai L.L., "Consequence-based robustness assessment of a steel truss bridge", Steel and Composite Structures, 14(4), 379-395, 2013.

[17] Tang M. L., Shen R. L. and Qiang S. Z., "Analytic theories and software development of spatial non-linearity static and dynamic of long-span suspension bridge", Bridge Construction, 30(1), 9-12, 2000.

[18] Sheikh I.A., Grondin G.Y. and Elwia A.E., "Stiffened steel plates under uniaxial compression", Journal of Constructional Steel Research, 58(5), 1061-1080, 2002.

[19] Luka P., Bernadette F., Ulrike K., Darko B., "Finite element simulation of slender thin-walled box columns by implementing real initial conditions", Advances in Engineering Software, 44(1), 63-74, 2012.

[20] Shi G., Liu Z., Ban H.Y., Zhang Y. Shi Y.J. and Wang Y.Q., "Tests and finite element analysis on the local buckling of $420 \mathrm{MPa}$ steel equal angle columns under axial compression", Steel and Composite Structures, 12(1), 31-51, 2011

[21] Yuan H.X., Wang Y.Q., Gardner L. and Shi Y.J., "Local-overall interactive buckling of welded stainless steel box section compression members", Engineering Structures, 67(8), 62-76, 2014

[22] Chatterjee S., The Design of Modern Steel Bridges, (Second Edition), Blackwell Science Ltd, London, 2008. 